Farum

Sociológico

\section{Forum Sociológico}

Série II

37 | 2020

Número 37

\title{
O Teatro Aberto em Lisboa : Notas de pesquisa sobre uma experiência de participação cultural
}

Teatro Aberto in Lisbon: Fieldwork notes on an experience of cultural participation

Vera Borges e Célia Caeiro

\section{(2) OpenEdition}

Journals

Edição electrónica

URL: https://journals.openedition.org/sociologico/9456

DOI: 10.4000/sociologico.9456

ISSN: 2182-7427

Editora

CICS.NOVA - Centro Interdisciplinar de Ciências Sociais da Universidade Nova de Lisboa

Edição impressa

Paginação: 27-37

ISSN: 0872-8380

\section{Refêrencia eletrónica}

Vera Borges e Célia Caeiro, «O Teatro Aberto em Lisboa : Notas de pesquisa sobre uma experiência de participação cultural», Forum Sociológico [Online], 37 | 2020, posto online no dia 23 dezembro 2020, consultado o 31 março 2022. URL: http://journals.openedition.org/sociologico/9456 ; DOI: https:// doi.org/10.4000/sociologico.9456 


\title{
O TEATRO ABERTO EM LISBOA: NOTAS DE PESQUISA SOBRE UMA EXPERIÊNCIA DE PARTICIPAÇÃO CULTURAL ${ }^{1}$
}

\section{TEATRO ABERTO IN LISBON: FIELDWORK NOTES ON AN EXPERIENCE OF CULTURAL PARTICIPATION}

\author{
Vera Borges \\ Centro de Investigação e Estudos de Sociologia (CIES-Iscte), Iscte - Instituto Universitário de Lisboa, Portugal \\ Célia Caeiro \\ Diretora de Comunicação do Teatro Aberto, Portugal
}

\begin{abstract}
Resumo
Este artigo tem um carácter exploratório e pretende descrever uma experiência de um "encontro" cultural com os públicos no teatro. Inspirada pelos debates recentes sobre a participação cultural e os pressupostos do programa europeu Be SpectACTive!, esta experiência promoveu um contexto de interação próxima de um conjunto de indivíduos com perfis heterogéneos e os profissionais da companhia Novo Grupo - Teatro Aberto, em Lisboa. A história deste teatro e as especificidades do seu trabalho artístico foram partilhadas durante o "encontro". Concluímos que os encontros com os públicos são micromomentos de participação cultural e diálogo que podem integrar-se nas missões, objetivos e atividades correntes das organizações teatrais e nas práticas e motivações dos seus responsáveis. $\mathrm{O}$ artigo utiliza as notas do diário de campo, as palavras dos responsáveis do teatro e uma sequência de fotografias que ilustram o percurso feito pelos participantes nos bastidores do teatro.
\end{abstract}

Palavras-chave: teatro, encontros, participação cultural, democracia cultural

\begin{abstract}
This article takes an exploratory approach and seeks to describe the experience of a cultural "encounter" with theatre audiences. Inspired on the recent debates around cultural participation and the assumptions of the European Be SpectACTive! program, this experience staged a frame of interaction between a set of individuals with heterogeneous profiles and professionals from the theatre company Novo Grupo - Teatro Aberto in Lisbon. The history of this theatre and the specific characteristics of its artistic work were shared over the course of this "encounter". We conclude that encounters with the public provide micro-moments of dialogue and cultural participation that may integrate both into the missions, objectives and current activities of theatrical organisations and into the practices and motivations of their leaders. This article deploys fieldwork notes, the declarations of those responsible for the theatre and a sequence of photographs that illustrate the path taken by these participants when backstage in the theatre.
\end{abstract}

Keywords: theater, encounters, cultural participation, cultural democracy

Ponto de partida: os "encontros" no teatro como micromomentos de participação cultural

O tema da participação cultural não é novo na literatura, mas a sua problematização ganhou uma nova relevância nos debates contemporâneos
(Belfiore, 2016; Belfiore e Gibson, 2019; Jancovich, 2015; Jancovich e Bianchini, 2013; Miles, 2016; Miles e Gibson, 2016). Se, por um lado, a literatura interroga os sinais de declínio da participação cultural; por outro lado, reflete até que ponto esse declínio não sugere afinal estilos de participação mistos, que agregam atividades culturais informais e de carác- 
ter quotidiano com atividades mais reconhecidas, esbatendo assim fronteiras e originando novos perfis de participação cultural (DiMaggio e Muktar, 2004; Taylor, 2016). As "arts talks", descritas por J. Conner (2013, pp. 137-168), e os "encontros", a que se refere T. Fradique (2019, pp. 19-20) no âmbito de uma reflexão mais ampla em torno do projeto "O público vai ao teatro", desenvolvido pelo grupo Teatro Meia Volta (Martins, Almeida e Duarte, 2019) -, são ferramentas culturais que representam e propõem formas diversas de participação e de relação com o mundo através dos artistas, das organizações artísticas e de outros participantes. Os "encontros" culturais e a observação dos "quadros ou molduras de interação" (Goffman, 1974) que entram em jogo revestem-se do maior interesse para uma análise sociológica mais fina do que podem ser os novos perfis-tipo de participação cultural, nos dias de hoje. Como defende J. T. Lopes (2019, p. 63), os "encontros" com os públicos nos teatros juntam

grupos de estranhos mediados por relações sociais de receção interpretativa, que os tornam menos estranhos: a si mesmos, às instituições, aos criadores. E que, no decorrer de um processo, possam experimentar não só novos conceitos, mas também novas formas coletivas de imaginação, experiência e organização.

É neste sentido que a literatura tem vindo a debater a participação cultural como um compromisso, uma aproximação aos indivíduos e grupos para que experimentem ver, sentir, falar sobre eventos, espetáculos, trabalhos culturais e artísticos, como forma de empoderamento dos cidadãos (Rancière, 2010 [2008]). A participação cultural favorece a confiança e promove práticas de cidadania ativa e, do lado das organizações artísticas, pode trazer maior consistência à sua identidade, promover a invenção de novas dinâmicas internas, dependentes do estilo institucional, do território cultural, do perfil da comunidade e da missão da instituição (Conner, 2013, p. 137; ver, também, Bonet e Schargorodsky, 2018). A literatura discute, ainda, a maior autonomia dos indivíduos nas suas escolhas culturais, pelo ecletismo das formas e linguagens que procuram, mas também pelo espectro mais amplo de expressões culturais que preferem e/ou realizam nos seus tempos livres e que são, igualmente, consideradas (Juncker e Balling, 2016). Por fim, na literatura destaca-se a importância da dimensão motivacional da participação cultural, em que estão envolvidos, por exemplo, os grupos de teatro amadores (Regenmortel, Mette, Donder e Elias, 2017). Esta dimensão implica fazer e participar nas atividades culturais enquanto formas de lazer e de realização intrínseca.
Do mesmo modo, Bonet e Négrier (2011a, 2011b, 2018a, 2018b) argumentam que a viragem das políticas públicas à participação ativa dos cidadãos, na Europa, em diferentes contextos culturais e artísticos (Dubois, 2015), apesar de não ser generalizada, nem coerente nas suas múltiplas formas, acompanha as mudanças tecnológicas, sociais e políticas das últimas duas décadas e a emergência da "democracia cultural expressiva" (Juncker e Balling, 2016). Os "encontros" com os públicos nos teatros podem tornar-se um bom exemplo da aplicação do conceito e das práticas alternativos de democracia cultural, conforme descrito e proposto por J. T. Lopes, para o caso português (Lopes, 2009, pp. 8-11). Por seu turno, o paradigma das políticas públicas para a cultura que mais valoriza a participação cultural dos indivíduos engendra também lógicas de cocriação e cocuradoria (Markusen e Brown, 2014) que, até um certo ponto, estão na génese de práticas colaborativas alternativas com efeitos interessantes na criação teatral portuguesa².

Da mesma forma, Walmsley (2013) chamou a atenção para a tendência crescente da cocriação no teatro e considerou que os "encontros" com diferentes grupos durante o processo criativo podem aumentar a participação de novos públicos e ajudar a desenvolver experiências imersivas com os públicos já existentes. No entanto, o autor sublinha os limites da cocriação enquanto ferramenta para democratizar as experiências culturais e mostra como esta pode originar circuitos destinados apenas aos públicos "conhecedores", conferindo um carácter elitista às experiências culturais (Walmsley, 2013, p. 116).

Compreende, assim, que a importância da participação cultural não se dá tanto pela possibilidade de cocriação, mas antes pelo conteúdo da missão dos nossos teatros, que deveriam ter mais condições, tempo e dinheiro para o "aprimoramento" de experiências culturais múltiplas com os públicos ( $v$. Boorsma, 2006): por exemplo, promovendo abordagens distintas em função de uma segmentação motivacional dos participantes aos quais se dirigem e uma atuação por "grupos de públicos" com interesses e perfis diferenciados. É nesse sentido que se considera relevante promover os "encontros" nos teatros, pois assim se dará a conhecer o quotidiano das organizações, os seus projetos, as suas missões artísticas, culturais e sociais. E, por isso, temos vindo a chamar a atenção para as formas como os responsáveis dos teatros e os stakeholders locais devem repensar estes espaços, as suas missões, os impactos e desafios à sua sustentabilidade cultural, e mais-valias que se anteveem pela sua vivência por parte de diferentes grupos de participantes (Borges, 2017a, 2017b, 2019; Throsby, 2017).

Neste artigo descreve-se uma experiência de "encontro" cultural com os públicos no teatro. Esta experiência foi inspirada pelos debates recentes 
sobre a participação cultural e os pressupostos do programa europeu Be SpectACTive!, "abrir as portas" dos teatros, fora dos contextos de receção dos espetáculos, promover momentos de encontro e diálogo público com habitantes locais, audiências mais críticas ou menos, amadores, voluntários, estagiários, estudantes, públicos que se tornam embaixadores destas organizações, são experiências que desafiam os participantes e os teatros e que podem integrar-se, de forma estruturada e regular, nas missões, nos objetivos e nas atividades das organizações artísticas, nas práticas e motivações dos seus responsáveis (Brown, Novak-Leonard e Gilbride, 2011). Nas ações desenvolvidas no âmbito do projeto de pesquisa-ação europeu Be SpectACTive! descreve-se uma pluralidade de ferramentas que podem promover diferentes modalidades de participação dos públicos e microgrupos, naquilo que pode ser uma aproximação dos cidadãos aos teatros e que inspirou este encontro que realizámos no Teatro Aberto, com o Novo Grupo, em Lisboa ${ }^{3}$.

\section{Metodologia}

O "encontro" com os participantes no teatro e os objetivos específicos

O paradigma da democracia cultural prevê uma atuação transversal das políticas públicas para a cultura, desde a criação, mediação, distribuição até à receção dos trabalhos artísticos; e visa prolongar uma aproximação empática dos públicos ao ato criador, às organizações e aos seus quotidianos, através de intervenções regulares que sejam enriquecedoras para todos os tipos de públicos, como é defendido por J. T. Lopes, numa abordagem ao caso português (Lopes, 2007, 2009). Deste modo, e tendo em conta os pressupostos analíticos do programa europeu Be SpectACTive!, desenvolvemos uma experiência de encontro cultural no teatro para promover uma ação de envolvimento dos públicos. Procurámos fazê-lo com o Teatro Aberto, dirigido pelo Novo Grupo, fundado nos anos 1980, situado na Praça de Espanha, em Lisboa. Na universidade, o encontro foi enquadrado pelas talks que a investigadora V. Borges organiza no Iscte - Instituto Universitário de Lisboa. Estas conversas procuram trazer os artistas à universidade para desvendar as missões, os tempos e os quotidianos de trabalho nas artes ${ }^{4}$. Mas, no caso deste "encontro" cultural, os participantes foram ao teatro e a experiência foi pensada em parceria com a diretora de comunicação e marketing, C. Caeiro, com o apoio dos diretores do teatro, J. Lourenço (encenador) e V. San Payo de Lemos (dramaturgista).

Com este "encontro" cultural, tivemos quatro objetivos específicos: (i) procurámos desenvolver um encontro, no sentido abordado na primeira parte do artigo, como uma experiência de participação cultural in vivo em que os participantes, com diferentes perfis escolares e profissionais, se encontram nos bastidores do teatro para conhecer como este se organiza, que equipas ali trabalham e como se construiu o espetáculo a que assistiriam; (ii) promover o envolvimento dos públicos no trabalho das diferentes equipas de profissionais do teatro; (iii) refletir sobre os efeitos possíveis destes encontros; e, por fim, (iv) deixar pistas para o aprofundamento de uma pesquisa sobre quem são os participantes dos "encontros" e como podemos promover um maior envolvimento cultural destes públicos no teatro.

\section{A recolha exploratória de dados}

Para atender aos objetivos específicos, concebemos a estrutura do "encontro" no teatro, pensando nos diferentes momentos em que se faria a aproximação do teatro ao público: a partilha da história do teatro, e das histórias das pessoas que dele fazem parte, a visita aos espaços do teatro, à sala onde iria decorrer o espetáculo, as conversas com as suas equipas técnicas e artísticas, a apresentação do modelo de comunicação com os públicos, o espetáculo de teatro e a reflexão em torno do mesmo (no caso dos estudantes de mestrado, esta reflexão crítica foi feita em situação de seminário, do mestrado em Estudos de Teatro, na Faculdade de Letras, da Universidade de Lisboa) ${ }^{5}$. 0 encontro foi promovido pela equipa de comunicação, no Iscte - Instituto Universitário de Lisboa, com o apoio da equipa de comunicação do Teatro Aberto. Começámos por utilizar a fotografia do espetáculo em cena, intitulado A Mentira, de F. Zeller, com os dois atores principais na imagem. Construímos um bilhete-happening que previa um encontro do público em diálogo com as diferentes equipas do teatro. Utilizámos os media online, Facebook e as mailing lists do centro de investigação e do teatro, e a divulgação direta feita junto dos nossos estudantes.

A seleção deste teatro teve em conta a perceção de que o seu trabalho se desenvolve de forma coerente ao longo dos anos, e a sua missão cultural tem uma moldura contextual que pode representar um caso de estudo para o desenvolvimento regular destas ações com os públicos. O projeto preparou-se ao longo dos meses de fevereiro e março de 2019, com o apoio do teatro. Os participantes foram informados, durante a fase da comunicação, dos pressupostos analíticos do encontro. Durante o encontro, procurámos fazer o registo preliminar das relações sociais neste contexto de diversas interações e anotámos os relatos produzidos pelos profissionais, no dia do encontro (13 de março de 2019). A recolha dos depoimentos e notas de campo ficou formalizada com a colaboração das equipas artísticas, a encenadora M. Dias, o ator F. Pestana, 
o técnico M. Verdades, os diretores, o encenador, J. Lourenço (destacamos o registo de uma conversa informal, anterior a este encontro), a dramaturgista, V. San Payo de Lemos, e a diretora de comunicação, C. Caeiro. A dramaturgista e diretora do teatro respondeu, ainda, a um conjunto de questões sobre o background da estrutura e os seus desafios atuais, em que destacou a relação antiga e de confiança com os públicos e a sua procura permanente de outras audiências (San Payo de Lemos, entrevista escrita, 13.10.2019). Cada um dos excertos das palavras ditas e escritas pelos intervenientes tem o seu consentimento, assim como as fotografias utilizadas. Estas foram feitas e escolhidas pela equipa de comunicação do teatro para ilustrar alguns dos momentos da experiência cultural, mas mostram também o valor que a equipa atribui à produção e comunicação da sua marca, Teatro Aberto. Alguns destes registos do diário de campo estão destacados em blocos de texto, a cinzento, para chamar a atenção do leitor e facilitar a sua leitura.

Durante o "encontro" cultural foram focadas as dimensões históricas do teatro em Portugal, os seus desafios desde os anos 1970, as histórias e perceções dos atores mais antigos sobre o impacto deste teatro no meio artístico português, as suas atividades correntes, o trabalho teatral, as tarefas das diferentes equipas e as suas motivações. Houve um interesse particular pela arquitetura deste teatro por parte dos estudantes que investigam as especificidades arquitetónicas dos teatros, no Mestrado em Arquitetura do Iscte - Instituto Universitário de Lisboa.

\section{Resultados preliminares: três notas de pesquisa}

A importância de repensar em conjunto as múltiplas missões do teatro

Os participantes foram acolhidos no foyer, onde estava exposta uma seleção de fotografias dos espetáculos realizados pelo Novo Grupo, ao longo de 40 anos. Neste espaço decorrem exposições, colóquios, entre outras iniciativas culturais. F. Pestana (1951), ator permanente da companhia desde a sua fundação, em 1982, é hoje membro da direção da cooperativa e foi o responsável por contar a história da companhia e o movimento dos grupos de teatro independentes nos anos 1970. Um momento de grande cumplicidade com os participantes.

Os participantes eram estudantes (dez, sendo dois deles estudantes brasileiros), alunos de mestrado, uma produtora de uma estrutura de dança, um diretor de uma estrutura teatral, situada fora de Lisboa, Avancas, uma professora universitária especialista em Métodos Quantitativos, espetadora habitual do Teatro Aberto, dois professores do ensino
Figuras 1 a $3 \triangleright 0$ encontro dos participantes com os profissionais do teatro no foyer
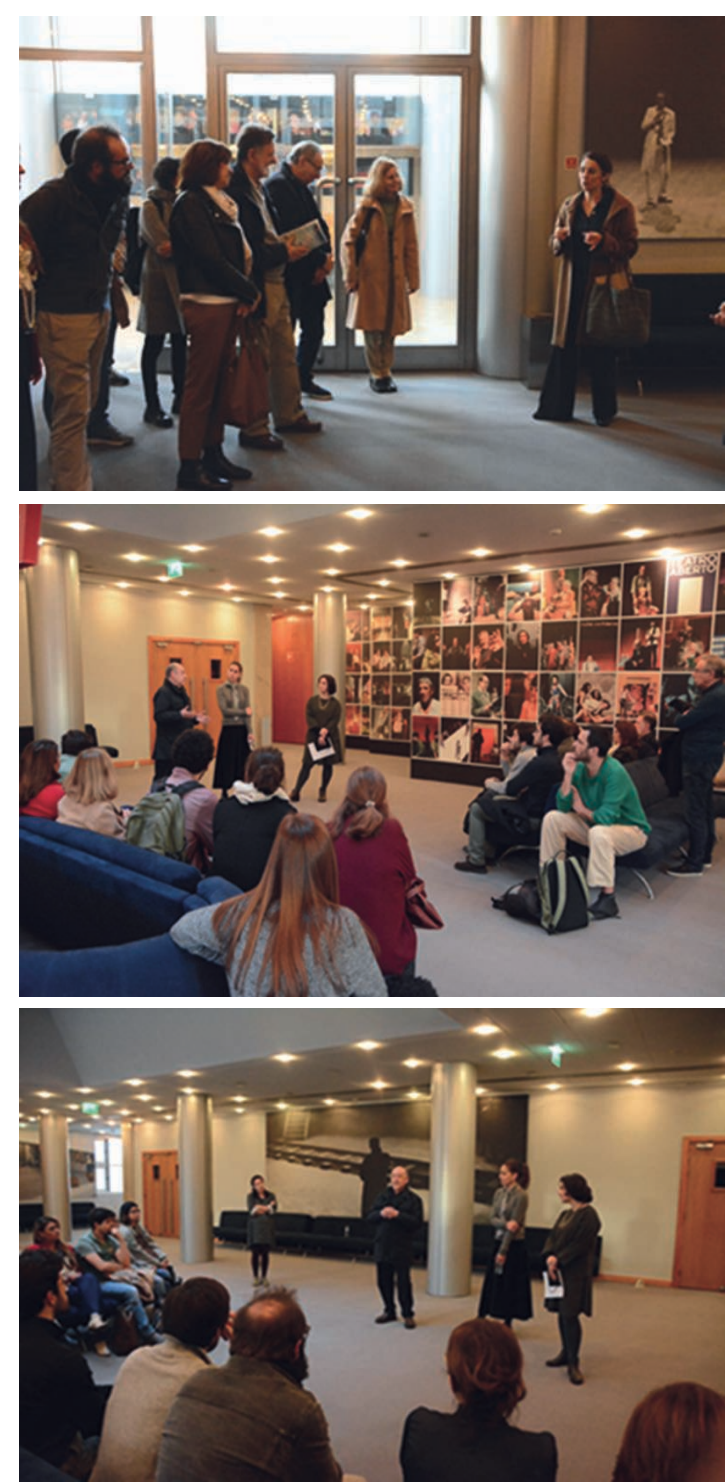

(C) Teatro Aberto

secundário, um professor universitário reformado, uma enfermeira, uma estudante de doutoramento em Políticas Públicas, dois estudantes do mestrado em Arquitetura do Iscte - Instituto Universitário de Lisboa, e uma historiadora da arte, investigadora do CHAIA - Centro de História da Arte e Investigação Artística, situado em Évora. Os estudantes que compareceram frequentavam o mestrado em Estudos da Cultura ministrado no Iscte - Instituto Universitário de Lisboa e o mestrado em Estudos de Teatro, da Faculdade de Letras, da Universidade de Lisboa. As idades dos intervenientes variavam entre os 22 e os 70 anos e os seus perfis profissionais eram, apesar de tudo, relativamente heterogéneos. 
A história do Teatro Aberto tem origem no Grupo 4, criado em 1966 pelos atores I. Cruz (1943), J. Lourenço (1944), M. e Castro (1939-2009) e R. Mendes (1937). Este grupo distinguiu-se por ser independente do circuito de teatro comercial da época: "Eram grupos que tinham uma frescura que o Teatro Nacional não possuía e não tinham os interesses comerciais dos empresários da época. A prática teatral era um espaço de afirmação política e de autonomia ideológica", acrescentou C. Caeiro. Em 1973, depois de sete anos sem sala própria (o grupo apresentava os seus espetáculos sobretudo no Teatro Tivoli), começou a construção do primeiro Teatro Aberto, que veio a ser inaugurado em 1976. O espetáculo de estreia foi O Círculo de Giz Caucasiano, de B. Brecht, com encenação de J. Lourenço. Este foi considerado pela crítica um dos maiores êxitos do teatro após o 25 de Abril. A peça esteve em cena durante mais de um ano e "os espetadores vinham de vários pontos do país, faziam piqueniques nos jardins da Gulbenkian e assistiam ao espetáculo", afirmou C. Caeiro.

Em 1978, J. Lourenço viajou para Berlim, a convite do Berliner Ensemble - teatro dirigido por Manfred Wekwerth - e participou na encenação da nova versão de Mãe Coragem e os Seus Filhos, de B. Brecht. Em 1980, no regresso de Berlim, J. Lourenço encena a peça Baal, no Teatro da Trindade. Após esse espetáculo, o encenador cria uma nova companhia para o Teatro Aberto, que integra, entre outros, os atores M. Viegas e I. Cruz; e, ainda, F. Pestana e M. Teixeira, que tinham saído, entretanto, de um outro grupo independente chamado $A$ Comuna (sediado na Praça de Espanha, em Lisboa). Em 1982, o Novo Grupo de Teatro, nome que a equipa escolheu para a nova companhia, estreia o seu primeiro espetáculo: Oiçam como Eu Respiro, de Dario Fo/Franca Rame.

A atividade do Novo Grupo continuou nos anos seguintes. Em 1984, a Câmara Municipal de Lisboa tornou pública a sua vontade de retomar a posse do terreno onde se situava o primeiro Teatro Aberto, na Praça de Espanha. Iniciou-se a negociação com a autarquia. Como alternativa à saída definitiva daquela praça, o grupo propôs que se construísse um novo Teatro Aberto, e que este fosse cedido ao Novo Grupo. A construção do novo Teatro Aberto demorou 18 anos. Neste projeto do arquiteto A. Matos Salgueiro, a equipa do teatro utilizou a sua experiência técnica. O novo Teatro Aberto foi inaugurado em 2002, pelo então presidente da República, Jorge Sampaio.

O encontro pode produzir "redes de reciprocidade" entre os participantes e as equipas do teatro

Ao entrarmos na Sala Azul, C. Caeiro e M. Dias chamaram a atenção dos participantes para as características físicas da sala. A zona de circulação é feita junto às paredes da sala, pelas coxias e não pela zona central, permitindo que os espetadores ocupem os lugares com melhor visibilidade.

Esta sala tem nove varas de iluminação de plateia, o que é muito pouco comum. São varas elétricas que não estão escondidas e permitem uma iluminação de frente para que se possa sempre sublinhar a expressão dos atores. Ainda sobre a plateia, existe uma ponte rolante que, na época em que o teatro foi construído, era única. Esta ponte permite que o técnico se possa deslocar livremente por cima da plateia, junto das varas onde estão os projetores para direcionar a luz, manualmente, para onde se deseja. Outro aspeto importante da sala é a inclinação da plateia. Esta inclinação não se prende apenas com a visibilidade para o palco, que é excelente, mas também foi pensada em função da propagação do som. O teto é também em curva, formando o que se designa por concha acústica. (Palavras de C. Caeiro, durante o encontro no teatro, lidas e corrigidas posteriormente.)

A lotação máxima da sala é de 418 espectadores. Tem duas plataformas elevatórias no início da plateia, depois da boca de cena, com três posições: o fosso de orquestra, utilizado quando são apresentados espetáculos de ópera ou musicais; uma posição intermédia que permite que sejam acrescentadas quatro filas à plateia; e uma terceira posição ao nível do palco que permite criar o avant scène. A sala conta com uma estrutura modular que permite encobrir seis filas da plateia, ocultando 117 lugares, utilizados apenas quando necessário. Saímos da Sala Azul. M. Dias, encenadora e responsável pelo programa educativo do Teatro Aberto, convidou os participantes para a Sala do Programa Educativo, onde podemos ver as fotografias do antigo teatro, os programas dos espetáculos da companhia, muitos figurinos e maquetes dos cenários. Foi um momento que captou especial atenção nos participantes interessados em arquitetura e espaços teatrais.

M. Dias chamou a atenção para a maquete restaurada do cenário do espetáculo 0 Tempo e o Quarto (1993). Referiu a importância desta maquete como um valioso instrumento para o trabalho da equipa de encenação do teatro. Com a maquete, o encenador visualiza o espaço cénico, a movimentação dos atores, e prepara a marcação dos movimentos, o que depois será experimentado em palco, durante os ensaios com os atores.

Descemos em direção ao palco. M. Verdades (1970), mestre da carpintaria e maquinista da equipa permanente do Teatro Aberto, descreveu a maquinaria de cena. 
Figuras 4 e $5 \triangleright M$. Dias descreve os figurinos e as maquetes ao grupo de participantes
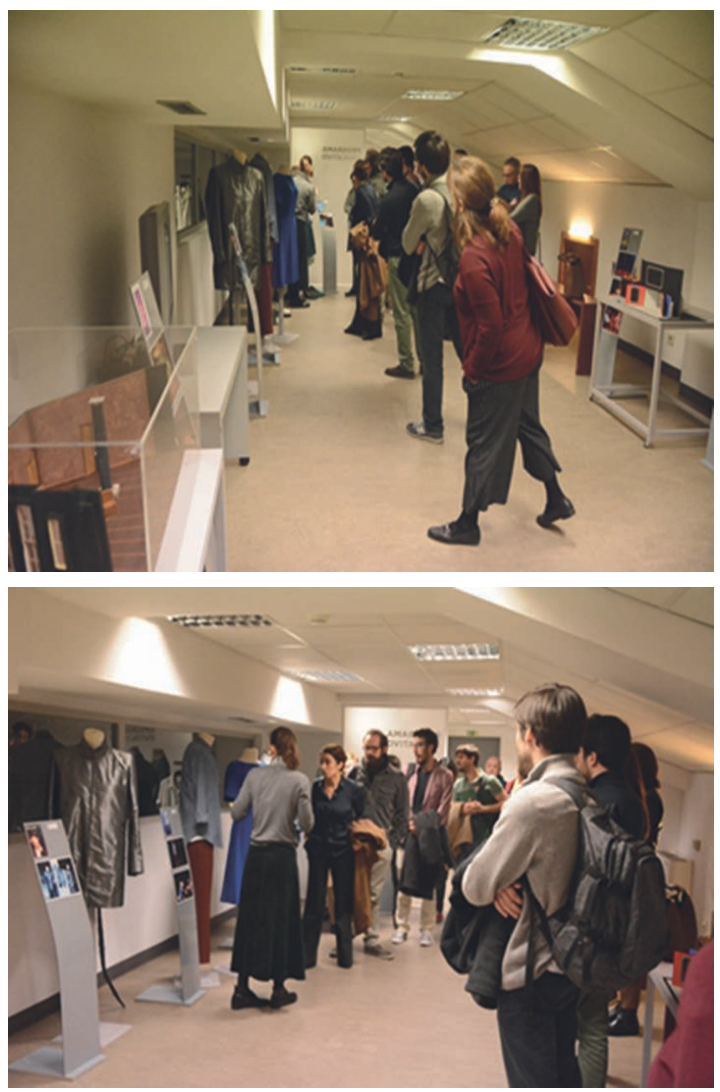

(c) Teatro Aberto

No palco da Sala Azul existem as varas elétricas e manuais, onde podem ser colocados projetores de luz, cortinas, bambolinas ou elementos do cenário. O mestre da carpintaria indica onde fica a boca de cena e a bambolina régia. Quando se monta o cenário, fixa-se a altura da bambolina régia e das outras bambolinas (faixas de pano preto que atravessam o palco em largura), que existem para que não se vejam os projetores de luz e outros elementos do cenário ou da maquinaria, suspensos nas varas. Outra característica da Sala Azul é a sua teia de madeira, muito versátil, que se adequa às cenografias dinâmicas, características do trabalho artístico do grupo. O palco desta sala está ligado à oficina onde os cenários são construídos. O teatro tem uma equipa permanente de carpintaria e maquinaria de cena. Acompanhámos o mestre da carpintaria ao subpalco e observámos o elevador do palco. Este elemento, inicialmente concebido para o transporte dos cenários da oficina para o subpalco e para a Sala Vermelha, foi depois modificado para permitir que fossem montados elementos do cenário no elevador que pudessem subir para cena, ampliando as valias da maquinaria do palco da Sala Azul. O palco está dividido em quarteladas, para que elementos do cenário possam subir e descer para o subpalco. Num dos lados do subpalco, observámos os motores das varas do palco que correm em carris para que as varas motorizadas se possam fixar em qualquer posição necessária para a cenografia ou a iluminação dos espetáculos. (Notas do diário de campo, posteriormente transcritas e corrigidas por C. Caeiro.)

Antes de visitarmos o segundo espaço de representação do Teatro Aberto, denominado Sala Vermelha, espreitámos a zona dos elevadores do fosso de orquestra, que, naquele momento, estava na posição de plateia. Quando os elevadores estão na posição mais baixa é pelo subpalco que se faz a entrada dos músicos no fosso de orquestra. Continuámos em direção à zona dos camarins. O grupo estava cada vez mais próximo dos profissionais do teatro, ganhando confiança e fazendo perguntas.

Figura $6 \triangleright$ O mestre da carpintaria com os participantes no encontro

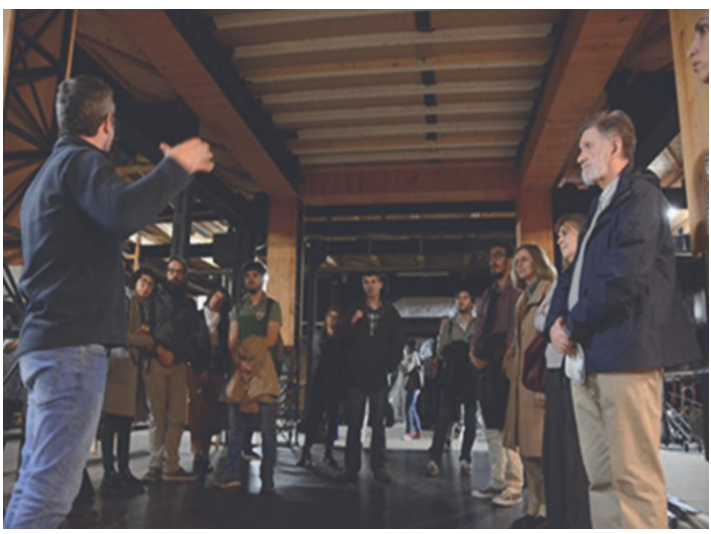

(C) Teatro Aberto

Detivemo-nos no camarim do ator F. Pestana. Um espaço íntimo, resguardado, que se abriu para nos mostrar uma vida no teatro: veem-se os cartazes que o ator guarda dos espetáculos mais marcantes da sua carreira como, por exemplo, Mãe Coragem e os Seus Filhos, de B. Brecht, Oleana, de D. Mamet. Virámos à direita para ver a tabela de serviço. Nesta tabela estão os horários das atividades que decorrem no teatro, informando-se assim os colaboradores internos e externos sobre as atividades a decorrer, para melhor coordenação das equipas. Seguimos em frente e descemos as escadas que passam pela Sala Verde, um espaço 
Figura $7 \triangleright$ Os participantes sobem ao palco da Sala Azul, onde estão as pinturas que integravam o cenário de A Mentira (2019)

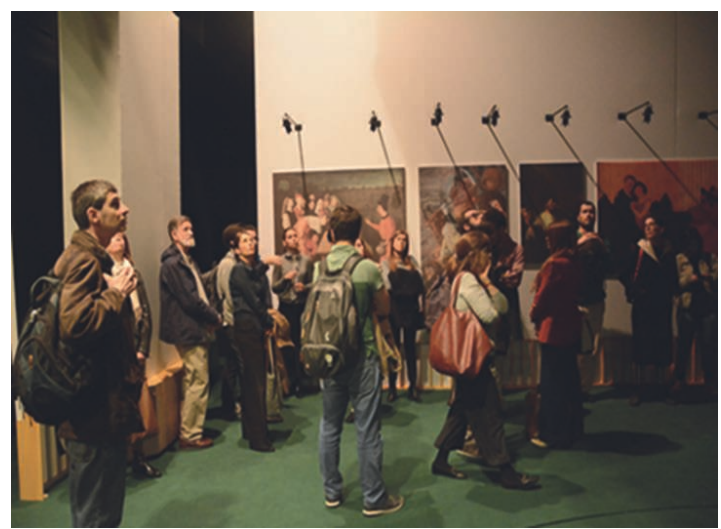

(c) Teatro Aberto

que serve de bastidores à Sala Vermelha. Nesta sala, os participantes procuraram ver o que estava escondido por detrás dos cenários da peça $A$ Verdade, em cena em simultâneo com a peça $A$ Mentira, na Sala Azul. A plateia desta sala é móvel, permitindo várias configurações, podendo até ser colocada de um lado e do outro da área de representação, como aconteceu por exemplo no espetáculo Copenhaga, de M. Frayn. A sala tem um subpalco com cerca de $90 \mathrm{~cm}$, não tem teia, mas uma grelha de metal que desce para se montarem os projetores de luz e uma estrutura de tubos e varas, onde também se montam projetores. A afinação para dirigir a luz é feita com escadas ou através de arnês.

Figura $8 \triangleright$ Os participantes com a responsável pela equipa de comunicação, na Sala Vermelha



(c) Teatro Aberto

Esta sala cria uma empatia com os espectadores, algo que os nossos participantes também sentiram. A zona de representação está ao nível do público. Assim, conseguimos ouvir e sentir a respira- ção do ator; o que confirmámos, depois, durante o espetáculo. Neste palco foram representados, entre muitos outros textos, todas as peças vencedoras do Grande Prémio de Teatro Português, promovido pela companhia do Teatro Aberto com a Sociedade Portuguesa de Autores. Nesta altura, era forte a cumplicidade que cada interveniente tinha criado com os elementos da equipa artística, técnica e de comunicação, gerando-se "redes de reciprocidade" (Keaney, 2006).

O "encontro" como um quadro de interações próximas e outras relações de receção

Na Sala de Movimento, espaço usado para ensaios de música, exercícios de aquecimento e para encontros como este, C. Caeiro perguntou aos participantes como entendiam o nome do grupo. Muitos deles, sobretudo os mais jovens, desconheciam a origem do nome Teatro Aberto.

Estávamos num período revolucionário em que os nomes eram importantes e o teatro queria-se aberto a todos. Fui contra ser um nome de um ator conhecido, como os casos do Teatro Villaret, Vasco Santana, ou do Maria Matos, porque passados uns anos já não se liga o espaço a essas pessoas. A ideia surgiu da vontade de apresentarmos um tipo de teatro sem classes, aberto a todo o público, e queríamos que o próprio teatro tivesse essa intenção no nome. $O$ teatro era aberto a toda a gente. Quando mudámos para o novo Teatro Aberto também houve uma preocupação na escolha do nome das salas, escolher nomes que fossem próximos dos espectadores e optámos pelas cores, Sala Azul e Sala Vermelha. (Palavras de J. Lourenço, durante uma conversa informal com C. Caeiro, realizada antes do encontro.)

A companhia procurou sempre a comunicação com os espectadores. A sua programação distingue-se pela escolha de dramaturgias contemporâneas. Outro traço merecedor de destaque prende-se com os tempos de carreira dos espetáculos do Teatro Aberto, que são sempre superiores a 30 representações. C. Caeiro destacou, ainda, a moldura contextual em que a companhia trabalha:

No Teatro Aberto, o dia do primeiro ensaio é um dia muito importante, porque é a primeira vez que se reúne toda a equipa do espetáculo e é o dia em que os atores leem o texto, pela primeira vez, enquanto toda a equipa o ouve. No final desta primeira leitura coletiva, cada elemento da equipa partilha as emoções que o texto lhe suscitou e a sua opinião sobre o que acabaram de ouvir. Apesar disso, o tra- 
balho sobre o texto começa meses antes do primeiro ensaio. Só o trabalho com o coletivo de artistas é que começa nesse dia. Tiramos então fotografias dos ensaios, elaboramos a sinopse, compomos a ficha artística e começamos a trabalhar na comunicação e na imagem do cartaz. (Palavras de C. Caeiro, durante o encontro, lidas e corrigidas posteriormente.)

A imagem do espetáculo e todos os materiais gráficos a ela associados, concebidos pela designer de comunicação do teatro, Mónica Lameiro, procuram ser apelativos e coerentes entre si, desde os anúncios na imprensa às imagens do Facebook e telões da fachada principal, voltada para a Praça de Espanha. Os programas dos espetáculos são cuidadosamente elaborados pela dramaturgista V. San Payo de Lemos, com a colaboração de M. Dias. Contêm as biografias dos autores e dos vários elementos da equipa criativa, os desenhos dos cenários e dos figurinos, as fotografias de ensaios e outros elementos que visam enriquecer a experiência do espectador. O próximo passo da equipa de comunicação é estabelecer parcerias e "criar a rede de comunicação de cada peça" (palavras de C. Caeiro, durante o encontro). Para a comunicação do espetáculo A Mentira, destacou-se a parceria do Teatro Aberto com a Antena 1, 2 e 3, o Metro de Lisboa, a Câmara Municipal de Lisboa (que lhes permite aceder à rede de mupis), a RTP e a BOL. Mas é preciso ir à procura dos públicos, construir as bases de dados, ter os endereços de correio eletrónico em mailing lists atualizadas e trabalhar de forma diferenciada para cada segmento de público. Hoje, cada vez mais, o teatro relaciona-se com influencers e/ou produtores de conteúdos digitais, como os bloggers. É importante lançar o espetáculo na comunicação social, e ter bons vídeos promocionais para apresentar no YouTube e para as redes sociais, em geral. Sem esquecer o site do Teatro Aberto (onde se encontram mais informações sobre o espaço e o trabalho da companhia) e em que são publicados diversos conteúdos audiovisuais destinados a promover o trabalho teatral. Um outro passo importante é a abertura das vendas na bilheteira online.

Nos últimos anos, as modalidades através das quais os públicos se informam mudaram muito. Não basta ao teatro enviar uma nota de imprensa e colocar anúncios nos jornais. A comunicação de um espetáculo de teatro é um trabalho diário. Antes da estreia, faz-se um dossiê de imprensa, um ensaio especial para os órgãos de comunicação social e enviam-se várias notas de imprensa. Após a estreia, comunicam-se os espetáculos na televisão, rádio e imprensa escrita. Tem-se vindo a investir menos nos anúncios na imprensa escrita e a apostar mais na comunicação online (que tem custos mais baixos) e chega a potenciais espectadores através das redes sociais: o Facebook, o Instagram e o YouTube. Estas são ferramentas importantes para a divulgação das atividades deste teatro. Por fim, é preciso "alimentar" as redes sociais com conteúdos específicos que devem ser diferenciados no Facebook e no Instagram. A equipa de comunicação incentiva as "partilhas" e a comunicação com os seus públicos virtuais, seduzindo-os a participar como espectadores e fidelizando-os.

Terminamos com as palavras da dramaturgista, V. San Payo de Lemos, sobre a forma como a principal missão do Teatro Aberto se mantém desde o início do teatro até aos dias de hoje:

Fazer do teatro um espaço de encontro, de pensamento sobre o mundo que nos rodeia, de emoção no contacto com a beleza ou a rudeza de sentimentos e situações; fazer do teatro um espaço de comunicação, de partilha de experiências, de conhecimento através da arte. (Palavras de V. San Payo de Lemos, escritas depois do nosso "encontro", no Teatro Aberto, 13.10.2019.)

\section{Notas finais e perspetivas para uma investigação futura}

Um dos instrumentos que está no centro da agenda cultural das políticas públicas para a cultura é a participação ativa dos cidadãos e dos públicos e o seu envolvimento com as organizações culturais. Este imperativo - nacional e europeu - implica uma nova abordagem às questões da participação cultural dos cidadãos e, em certos casos, exige a (re)definição da visão, das missões, dos objetivos, das estratégias, dos posicionamentos e das linhas programáticas dos teatros, dos seus grupos e companhias. Neste artigo, destacou-se a importância dos "encontros" no teatro, enquanto experiências de participação, que tornam "grupos de estranhos menos estranhos" a si mesmos e aos teatros, através das relações sociais que se estabelecem, tal como tem vindo a defender J. T. Lopes (2019, pp. 59-65).

Deixámos três notas de pesquisa, exploratórias, e que resultaram da experiência deste encontro, inspirada na literatura e nos princípios e lógicas do programa europeu Be SpectACTive!: (i) a importância de repensar em conjunto as missões das organizações teatrais; (ii) os encontros são micromomentos de participação cultural que podem gerar "redes de reciprocidade" com os teatros e promover o envolvimento dos indivíduos com as organizações; (iii) o "encontro" dá-se num quadro de interações próximas e promove outras relações de receção, para as quais as ferramentas digitais abrem caminho.

A valorização da participação dos cidadãos não gera por si só mais público nos contextos 
das artes performativas, mas faz-nos repensar as estratégias das organizações teatrais para criar novos/outros compromissos com os públicos. Ao promover uma interação mediada das estratégias de oferta e de procura, as organizações passam do marketing puro ao enriquecimento das propostas e dos seus públicos. Considera-se que as diferentes formas de envolvimento dos públicos, presencial, in loco, por via dos "encontros" culturais, regulares e estruturados, seja digital, através de mensagens, vídeos, podcasts - o Teatro Nacional D. Maria II e o Teatro do Bairro Alto, em Lisboa, têm sido dois bons exemplos -, facilitam a contextualização do trabalho artístico. O envolvimento com os públicos promove a sua participação, menos ritualizada, e melhora as "respostas emocionais" dos seus diferentes públicos (Walmsley, 2016). É um processo lento, mas profundo e relacional, que facilita a crítica construtiva, o diálogo em múltiplas dimensões como múltiplas são as biografias, trajetórias, origens sociais, competências e disposições destes públicos perante a cultura, e que estão, muitas vezes, "além do público-modelo" (Lopes, 2019, p. 63). Estas notas de pesquisa mostram a aposta forte do Teatro Aberto na abertura a novas formas de envolvimento presencial com os públicos.

Como perspetivas para uma investigação futura, consideramos que é possível - e desejável - conhecer melhor quem são estes grupos de participantes e desenvolver uma "etnografia dos públicos em ação", com as suas biografias, os seus contextos de socialização e o mapeamento de interações, tal como defende J. T. Lopes (2019, pp. 62-63) e, de igual modo, saber mais sobre as expectativas reais e potenciais destes públicos, a partir destes "encontros". Escutar e promover a partilha imediata de opiniões sobre o encontro realizado - por exemplo, neste grupo de participantes, onde alguns têm trajetórias prosumer - poderia fazer-se também através das plataformas web (v. Be SpectACTive!). Por fim, considera-se a importância de que se reveste a comunicação direta com os públicos e a relevância dos planos de marketing de um teatro (Stein e Bathurst, 2008) - equipa, tempo e dinheiro para os pensar e executar - e como estes micromomentos representam o "abrir das suas portas" a outras modalidades de participação cultural, com pequenas comunidades de espectadores e "embaixadores do teatro" (Brindle e Devereaux, 2011; Byrnes e Martn, 2003). É neste sentido que se considera fundamental repensar as relações das organizações teatrais com os seus parceiros locais (Stewart, 2005) como pilares de mediação pública, geradores de interações diversificadas, capazes de fortalecer os laços dos públicos com os seus teatros e os seus territórios.

\section{Notas}

1 Este texto respeita o Acordo Ortográfico de 1990.

2 No caso português, existem diferentes exemplos. Consultar, a este respeito, Borges, V. (2018), "Arte colaborativa. Uma observação localizada do teatro e dos seus públicos", Etnográfica, 22 (2), 453-476. E, ainda, Borges, V. (2020), "Observar os observadores n'O Bando. Como podem o teatro e a investigação científica ser tão desafiantes?" (CIES e-Working Paper, n. ${ }^{\circ} 229$ ), retirado de http://hdl. handle.net/10071/20590. A título ilustrativo, consultar a experiência francesa, descrita em Villagordo, É., Domergue, P. (2011), "Au croisement des postures sociologique et artistique: La résidence d'artiste Processus/Découpe", Tracés. Revue de Sciences Humaines, 11, retirado de http://journals.openedition.org/traces/5240.

3 Be SpectACTive! é um projeto europeu que promove a participação ativa dos cidadãos no domínio das artes performativas. O projeto existe desde 2014 e é cofinanciado pelo Programa Europa Criativa da União Europeia. Os membros que compõem a rede do programa são festivais, teatros, organizações culturais, universidades e um centro de pesquisa. O interesse da iniciativa é a sua aposta nas produções artísticas e práticas participativas destinadas a envolver os cidadãos, em geral, e os espetadores, nos processos criativos, mas também organizativos. Isto é feito com uma reflexão consequente sobre o programa à luz dos paradigmas das políticas para a cultura na Europa, os seus limites e as suas potencialidades: ver Bonet, L., e Négrier, E. (2018a), Breaking the Fourth Wall: Proactive Audiences in the Performing Arts, Elverum, Kunnskapsverket. Consultar, ainda, Bonet, L., e Négrier, E. (2018b), "The participative turn in cultural policy: paradigms, models, contexts", Poetics, 66, pp. 64-73. Por fim, o site do projeto e as suas páginas no Facebook e no Twitter: http://www.bespectactive.eu/, https://www.facebook. $\mathrm{com} / \mathrm{pg} /$ bespectACTive/about/?ref=page_internal; https:// twitter.com/bespectactive.

4 Consultar https://www.cies.iscte-iul.pt/np4/224/ e a ligação para podcasts Talk: https://www.cies.iscte-iul. $\mathrm{pt} / \mathrm{np} 4 / 225 /$.

5 Referência à disciplina de Políticas Públicas para a Cultura, lecionada pela investigadora V. Borges, na Faculdade de Letras da Universidade de Lisboa.

\section{Referências bibliográficas}

Belfiore, E. (2016). Cultural policy research in the real world: Curating "impact", facilitating "enlightenment" Cultural Trends, 25(3), 205-216. doi:10.1 080/09548963.2016.1204050

Belfiore, E., \& Gibson, L. (Eds.) (2019). Histories of cultural participation, values, and governance. Basingstoke: Palgrave Macmillan.

Bonet, L., \& Négrier, E. (2011a). The end(s) of national cultures? Cultural policy in the face of diversity. International Journal of Cultural Policy, 17(1), 1-16.

Bonet, L., \& Négrier, E. (2011b). La tension estandarizacion-diferenciacion en las politicas culturales. El caso de España y Francia. Gestion y Analisis de Politicas Publicas, 6, 53-73.

Bonet, L., \& Négrier, E. (Eds.) (2018a). Breaking the Fourth Wall: Proactive Audiences in the Performing Arts. Elverum: Kunnskapsverket. 
Bonet, L., \& Négrier, E. (2018b). The participative turn in cultural policy: Paradigms, models, contexts. Poetics, 66, 64-73.

Bonet, L., \& Schargorodsky, H. (2018). Theatre management: Models and strategies for cultural venues. Knowledge works: National Centre for Cultural Industries.

Boorsma, M. (2006). A strategic logic for arts marketing: Integrating customer value and artistic objectives. The International Journal of Cultural Policy, 12(1), 73-92.

Borges, V. (2017a). Cultural organizations, collaborative contexts and public: How they become small communities. Portuguese Journal of Social Science, 16(3), 359-76. doi:10.1386/pjss.16.3.359_1

Borges, V. (2017b). Os públicos-participantes. O teatro vai ao bairro. SOCIOLOGIA ON LINE, (14), 53-72. Retirado de http://revista.aps.pt/pt/os-publicos-participantes-o-teatro-vai-ao-bairro/

Borges, V. (2018). Arte colaborativa. Uma observação localizada do teatro e dos seus públicos. Etnográfica, 22(2), 453-476.

Borges, V. (Ed.) (2019). Paradigmas das políticas públicas para a cultura e os equipamentos culturais: Cinco micro-estudos sociológicos. Iscte: Col. Reports.

Borges, V. (2020). Observar os observadores n'O Bando. Como podem o teatro e a investigação científica ser tão desafiantes? (CIES e-Working Paper, n. ${ }^{\circ} 229$ ). Retirado de http://hdl.handle.net/10071/20590

Brindle, M., \& Devereaux, C. (2011). The arts management handbook. Armonk, NI: ME Sharpe.

Brown, A., Novak-Leonard, J., \& Gilbride, S. (2011). Getting in on the act: How arts groups are creating opportunities for active participation. São Francisco: The James Irvine Foundation. Retirado de http://irvine.org/images/stories/pdf/grantmaking/ Getting-in-on-the-act-20110CT19.pdf

Byrnes, W., \& Martn, D. (2003). Management and the arts. Londres: Focal Press.

Conner, L. (2013). Audience engagement and the role of arts talk in the digital era. Nova Iorque: Palgrave Macmillan.

DimMaggio, P., \& Muktar, T. (2004). Arts participation as cultural capital in the United States, 19822002: Signs of decline?. Poetics, 32, 169-194. doi: $10.1016 /$ j. poetic. 2004.02 .005

Dubois, V. (2015). Cultural policy regimes in western Europe. In J. D. Wright (Ed.), International encyclopedia of social and behavioral sciences (2. ${ }^{a}$ ed.) (pp. 460-465). Oxford: Elsevier.

Fradique, T. (2019). O encontro performativo e o encantamento do mundo. In Teatro Meia Volta (Org.), o público vai ao teatro: Encontros sobre políticas da recepção e envolvimento de públicos no contexto das artes performativas (pp. 18-23). Maia: Maiadouro.

Goffman, E. (1974). Frame analysis: An essay on the organization of experience. Nova Iorque: Harper and Row.
Jancovich, L. (2015). The participation myth. International Journal of Cultural Policy, 23(1), 107-121. doi:10.1080/10286632.2015.1027698

Jancovich, L., \& Bianchini, F. (2013). Problematising participation. Cultural Trends, 22(2), 63-66. doi: $10.1080 / 09548963.2013 .783158$

Juncker, B., \& Balling, G. (2016). The value of art and culture in everyday life: Towards an expressive cultural democracy. The Journal of Arts Management, Law, and Society, 46(5), 231242.

Keaney, E. (2006). From Access to Participation Cultural policy and civil renewal. Londres: Institute for Public Policy Research.

Lopes, J. M. T. (2007). Da democratização à democracia cultural: Uma reflexão sobre políticas culturais e espaço público. Porto: Profedições.

Lopes, J. M. T. (2009). Da democratização da cultura a um conceito e prática alternativos de democracia cultural. Saber \& Educar, 14(14), 1-13. Retirado de https://www.researchgate. net/publication/276458003_Da_democratizacao da Cultura a um conceito e pratica_alternativos_de_Democracia_Cultural

Lopes, J. M. T. (2019). Recepção cultural e contra-públicos: Algumas notas para uma possibilidade de acção. In Teatro Meia Volta (Org.), o público vai ao teatro: Encontros sobre políticas da recepção e envolvimento de públicos no contexto das artes performativas (pp. 58-65). Maia: Maiadouro.

Markusen, A., \& Brown, A. (2014). From audience to participants: New thinking for the performing arts. Análise Social, 213(xlix, 4.ํ), 866-883.

Martins, A., Almeida, A., \& Duarte, S. (Orgs.) (2019). O público vai ao teatro: Encontros sobre políticas da recepção e envolvimento de públicos no contexto das artes performativas. Maia: Maiadouro.

Miles, A. (2016). Telling tales of participation: Exploring the interplay of time and territory in cultural boundary work using participation narratives. Cultural Trends, 25(3), 182-193. doi:10.1080/0 9548963.2016.1204046

Miles, A., \& Gibson, L. (2016). Everyday participation and cultural value. Cultural Trends, 25(3), 151-157. doi:10.1080/09548963.2016.1204043

Rancière, J. (2010 [2008]). O espectador emancipado. Lisboa: Orfeu Negro.

Regenmortel, S. V., Mette, T., Donder, L., \& Elias, W. (2017). Research note: The other side of the stage, revealing compositional differences in Flemish amateur theatre audiences. Leisure Studies, 36(4), 579-587. doi: 10.1080/02614367.2016.1203352

Stein, T. E., \& Bathurst, J. (2008). Performing arts management. Nova Iorque: Allworth Press.

Stewart, M. (2005). Collaboration in multi-actor governance. In M. Haus, H. Heinelt \& M. Stewart (Eds.), Urban governance and democracy: Leadership and community involvement (pp. 149-167). Nova Iorque: Routledge.

Taylor, M. (2016). Nonparticipation or different styles of participation? Alternative interpretations from 
taking part. Cultural Trends, 25(3), 169-181. doi: $10.1080 / 09548963.2016 .1204051$

Throsby, D. (2017). Culturally sustainable development: Theoretical concept or practical policy instrument?. International Journal of Cultural Policy, 23(2), 133-147. doi:10.1080/10286632.2017. 1280788

Villagordo, É., \& Domergue, P. (2011). Au croisement des postures sociologique et artistique: La résidence d'artiste Processus/Découpe. Tracés. Revue de Sciences humaines, (11), 29-45. Retirado de http://journals.openedition.org/traces/5240

Walmsley, B. (2013). Co-creating theatre: Authentic engagement or inter-legitimation?. Cultural Trends, 22(2),108-118. doi:10.1080/09548 963.2013 .783176

Walmsley, B. (2016). From arts marketing to audience enrichment: How digital engagement can deepen and democratize artistic exchange with audiences. Poetics, 58, 66-78.

Vera Borges. Socióloga, Investigadora Integrada do Centro de Investigação e Estudos de Sociologia (CIES-Iscte) do Iscte - Instituto Universitário de Lisboa, Portugal. Email: vera.borges@iscte-iul.pt

Célia Caeiro. Diretora de Comunicação do Teatro Aberto, Portugal. Mestre em Ciências da Comunicação, especialidade Comunicação e Gestão Cultural pela Universidade Católica Portuguesa. Email: celiacaeiro@ teatroaberto.com 